\title{
Health care utilization and changes in health status over time for migraineurs
}

\author{
Anderson Chuck PhD ${ }^{1,3}$, Philip Jacobs DPhil ${ }^{1,3}$, Arto Ohinmaa PhD ${ }^{1,3}$, Donald Schopflocher PhD ${ }^{4,3,1}$, \\ Saifudin Rashiq $M D^{2}$, Raquel Feroe $M^{5}$
}

\begin{abstract}
A Chuck, P Jacobs, A Ohinmaa, D Schopflocher, S Rashiq, $R$ Feroe. Health care utilization and changes in health status over time for migraineurs. Pain Res Manage 2007;12(4):291-295.
\end{abstract}

BACKGROUND: Determining how migraineurs manage their condition from the viewpoint of health resource utilization (including both medical and personal resources) may provide insights that could lead to more effective care strategies.

OBJECTIVES: To determine the relative importance of modifiable health-influencing activities for migraineurs, and to compare the effects of these activities between migraineurs and nonmigraineurs in the general population.

METHODS: Linear regression analysis was applied to all persons older than 19 years of age with migraine in the Canadian Community Health Survey Cycle 1.1. The dependent variable was reported health status change over time. Explanatory variables were a series of health care utilization, health behaviour and background control variables.

RESULTS: Results showed that health status was positively associated with higher levels of physical activity and negatively associated with smoking for both migraineurs and nonmigraineurs, even when controlling for all other variables.

CONCLUSION: By modifying controllable resources and behaviours, the reported health status of migraineurs can be improved as effectively as nonmigraineurs.

Key Words: Health care utilization; Health resources; Migraine; Pain management

$\mathrm{T}$ he prevalence of migraine in Canada has been estimated at 2.6 million adult women and 0.8 million adult men (1), and it affects all ages from infancy to old age (2). The associated direct and indirect costs are significant: it has been estimated that health care costs for persons with migraine are 1.6 times higher than for those without the condition (3). Migraineurs consume medical health care resources through medical consultations, emergency department visits and treatment $(4,5)$. Migraine peaks in individuals during the most productive years of life (6). Consequently, lost productivity due to migraine has been estimated to exceed $\$ 17$ billion annually in the United States $(7,8)$ and accounts for seven million annual lost working days in Canada (9).

The long-term management of migraine is challenging because of its complex etiology and the variable effectiveness of currently available treatment $(10,11)$. In addition, persons with migraine use personal resources that may potentially

\section{Utilisation des soins de santé et évolution de l'état de santé des migraineux}

HISTORIQUE : Déterminer comment les migraineux soignent leur maladie du point de vue de l'utilisation des ressources en soins de santé (incluant ressources médicales et main-d'œuvre), ce qui permettrait d'améliorer l'efficacité des stratégies thérapeutiques.

OBJECTIFS : Déterminer l'importance relative des activités modifiables influant sur la santé des migraineux et comparer leurs effets sur les migraineux et les non-migraineux dans la population en général.

MÉTHODES : Une analyse de régression linéaire a été appliquée à toutes les personnes migraineuses de plus de 19 ans dans le cadre de l'Enquête sur la santé des collectivités canadiennes (Cycle 1.1). La variable dépendante a été le changement signalé de l'état de santé avec le temps. La série de variables explicatives portait sur l'utilisation des soins de santé, le comportement face à la santé et des variables de contrôle de base.

RÉSULTATS : Les résultats ont montré que l'état de santé était en lien positif avec une plus grande activité physique et en lien négatif avec le tabagisme chez les migraineux et les non-migraineux, même après avoir tenu compte de toutes les autres variables.

CONCLUSIONS : En modifiant les ressources et les comportements contrôlables, l'état de santé rapporté des migraineux peut être amélioré aussi efficacement que chez les non-migraineux.

\footnotetext{
${ }^{1}$ Department of Public Health Sciences; ${ }^{2}$ Department of Anesthesiology 89 Pain Medicine, University of Alberta; ${ }^{3}$ Institute of Health Economics;

${ }^{4}$ Public Health Surveillance 83 Environmental Health, Alberta Health and Wellness; ${ }^{5}$ The LifeMark Health Institute, Edmonton, Alberta

Correspondence: Dr Philip Jacobs, Institute of Health Economics, \#1200-10405 Jasper Avenue, Edmonton, Alberta T5J 3N4.

Telephone 780-448-4881,fax 780-448-0018, e-mail pjacobs@ihe.ca
} 


\section{METHODS}

\section{Source of data}

The 2000/2001 Canadian Community Health Survey cycle 1.1 (CCHS 1.1) is a population-based health survey conducted by Statistics Canada as part of a federal initiative to provide health status and health resource utilization data. Specific details of the CCHS 1.1 have been published elsewhere (15). The CCHS 1.1 used a multistage stratified clustered sampling strategy. Data collection was conducted over 12 months beginning in September 2000, with the sample of households allocated randomly over the 12 -month period. The survey questionnaire was administered to a randomly selected household member by a trained interviewer either in person or over the telephone.

The CCHS 1.1 sample is representative of approximately $98 \%$ of the Canadian population aged 12 years or older in all provinces and territories (with the exception of First Nations reserves, Canadian military bases and certain remote areas). It provides information for each person in the sample on personal characteristics, health status, personal health behaviours and the utilization of health care services.

The CCHS 1.1 share file is a subset of the master file that contains respondents who agreed to share information with provincial health ministries. The share file contains full information on all variables collected in the CCHS, including bootstrap weights (15). It contains 125,574 respondents.

\section{Study sample}

The target population was all persons older than 19 years who responded to the question concerning self-reported change in health over the previous year: "Compared to 1 year ago, how would you say your health is now? Is it: much better than 1 year ago, somewhat better than 1 year ago, about the same, somewhat worse than 1 year ago or much worse than 1 year ago?" There were 109,788 respondents (87\%) meeting this criterion.

\section{Analysis}

The Health Production Function is a theoretical construct used in health economic research $(16,17)$ to guide empirical investigation of the relationship between resources and health outcomes. It regards the individual as a producer of his/her own health. Using this construct, health status change was conceptualized as a function of explanatory variables that represented resources used by the respondents in the production of health while also controlling for variables that might have increased or decreased his or her capacity for good health. Indicators of resource use included health behaviours (ie, health-influencing personal resources) and health care utilization (ie, medical care resources). Background control variables include demographics and health status information.

A linear regression model to predict self-reported change in health status over the previous year was constructed. Changes in health states were ranked from 1 (much worse) to 5 (much better). To realize this model as a linear regression analysis and to properly capture the relationship between MHIAs and changes in health status, the authors controlled for background variables and relevant interactions between these variables, and compared the effects of health-influencing behaviours on health status between migraineurs and nonmigraineurs (ie, the general population).

Personal health behaviour variables known to be related to migraine included cigarette consumption $(4,18)$, alcohol consumption (19) and physical activity (12,13). Cigarette consumption was dichotomized to compare current smokers [0] with nonsmokers. Alcohol dependence was based on the Composite International Diagnostic Interview (CIDI) Short Form for Alcohol Dependence. An 85\% predicted probability was used to indicate alcohol dependence. Physical activity, which was categorized as active, moderate and inactive, was included as a continuous variable. Levels of physical activity were derived in the CCHS 1.1, first by calculating the energy expenditure of specific activities (including sports, leisure, gardening and social activities) expressed as kilocalories expended (per kilogram of body weight per hour) per day for survey respondents, and second, by adding together their energy cost over all activities. Accordingly, inactive activity describes daily energy expenditures attributable to physical activities of $0 \mathrm{kcal} / \mathrm{kg}$ to $1.5 \mathrm{kcal} / \mathrm{kg}$, while moderate and active levels of activity describe daily energy expenditures of $1.5 \mathrm{kcal} / \mathrm{kg}$ to $2.9 \mathrm{kcal} / \mathrm{kg}$ and $3.0 \mathrm{kcal} / \mathrm{kg}$ or greater, respectively. The relationship between physical activity and the dependent variable was examined, which uncovered a linear relationship. Therefore, physical activity was treated as a continuous variable.

Variables that represented resource use of health care services included medical and alternative health care services. Medical health care utilization variables included visits to a family physician, visits to a specialist physician and whether the person was hospitalized in the past year (for any reason). The number of visits to family and specialist physicians was derived by asking the respondent the number of times they had come into contact with a family or specialist physician over the previous year. The alternative health care utilization variable was whether the individual visited [1] or did not visit [0] an alternative health care provider. Alternative care providers were identified in the survey as being acupuncturists, homeopaths or massage therapists. Data on hospitalization in the previous year were included as a no [0] and yes [1]. Approximately $65 \%$ of data on the use of pain medications were missing from the target population and therefore, this variable was not included in the final analysis. Explanatory control variables included sociodemographic variables and comorbidities. Migraine is known to be prevalent between the ages of 30 to 40 years (6); it is more common and severe in women $(1,20,21)$, and is associated with educational attainment (22). Therefore, sociodemographic variables were the respondent's age, sex and education. Men and women were coded as [0] and [1], respectively. Education was hypothesized to reflect one's ability to use resources more effectively and was categorized as less than a high school graduate, high school graduate, some postsecondary or postsecondary graduate in the CCHS 1.1. Education was recoded into three dummy variables indicating high school graduate versus less than high school graduate, some postsecondary versus less than high school graduate, and postsecondary graduate versus less than high school graduate. Furthermore, the interactions between sex and age, and sex and education, were included in the model.

The absence [0] or presence [1] of migraine was included in the model to quantify differential affects between migraineurs and nonmigraineurs. The absence [0] or presence [1] of specific chronic conditions was also included to control for comorbidities commonly associated with migraine. These included cardiovascular conditions (heart disease or high blood pressure) (18,23) and allergies (23). Moreover, 
migraine has features common with episodic (ie, occurrence of self-limited attacks of pain) and chronic pain disorders (ie, an enduring predisposition to pain) (24) and is also commonly associated with depression (25-27). Therefore, the presence of musculoskeletal pain (arthritis, fibromyalgia or back pain) and depression were included in the regression model. With the exception of depression, included chronic conditions were indicated in the CCHS 1.1 by self report via the question "We are interested in conditions diagnosed by a health professional. Do you have 'condition'?" Indications of depression were based on the CIDI Short Form for Major Depression (CIDI-SFMD). Depression on the CIDI-SFMD corresponds to symptomatic depression according to the Diagnostic and Statistical Manual of Mental Disorders Version III criteria. A 90\% predicted probability on the CIDI-SFMD indicates the presence of depression (28). To determine whether the presence of migraine changed the nature of the relationships between MHIAs and health care utilization variables, two-way interactions between migraine and all explanatory variables, as well as a three-way interaction among migraine, age and sex in the model were alse included.

The analysis used weighting to correct estimates for the effects of the complex survey design. Specifically, weights rescaled to the total actual sample size were used - a frequently suggested form of analysis (29). Statistical significance was determined for estimated parameters by using bootstrap-generated standard errors (15). Model coefficients were considered statistically significant at $\mathrm{P}<0.05$. SPSS for Windows 13.0 (SPSS Inc, USA) was used for all statistical analyses.

\section{RESULTS}

The data were analyzed both by excluding cases with missing data on independent variables and by including missing cases (with imputed data). The results did not change. The analysis excluding missing data is presented. There were 98,530 respondents (90\% of target population) with complete data. Table 1 shows the characteristics of the target sample population and migraine population within the target sample. The prevalence of migraine in the sample was $9.7 \%$.

Compared with one year previously, a greater proportion of migraineurs reported better health status than the general target sample population, with approximately the same proportion reporting worse health status. A greater proportion of migraineurs were current smokers, and there was approximately the same proportion of respondents who were alcohol dependent or physically inactive.

Over the year, migraineurs had more visits to family and specialist physicians, and a greater proportion visited an alternative care provider or was hospitalized. Musculoskeletal pain, cardiovascular conditions and allergies were more prevalent in the migraine population.

\section{Regression analysis}

Of the control variables, age $(\beta=-0.003)$ and the presence of a musculoskeletal condition $(\beta=-0.08)$ were associated with a negative health change, while female sex $(\beta=0.058)$ and being a high school graduate $(\beta=0.017)$ were associated with positive health change $(\mathrm{P}<0.05)$. Table 2 shows the regression results for noncontrol variables and model interactions. Of the modifiable health behavioural factors, smoking was associated with a negative health change, while physical activity was associated with a positive health change $(\mathrm{P}<0.05)$.
TABLE 1

Characteristics of study populations

\begin{tabular}{|c|c|c|}
\hline Variable & $\begin{array}{c}\text { Target } \\
\text { sample* }^{*}\end{array}$ & $\begin{array}{c}\text { Migraine } \\
\text { sample }^{\dagger}\end{array}$ \\
\hline \multicolumn{3}{|l|}{ Change in health status over previous year } \\
\hline Much better & 1.6 & 8.2 \\
\hline Somewhat better & 10.0 & 12.5 \\
\hline Same & 71.1 & 62.1 \\
\hline Somewhat worse & 10.8 & 13.6 \\
\hline Much worse & 6.5 & 3.6 \\
\hline \multicolumn{3}{|l|}{ Demographic variables } \\
\hline Age, years (mean $\pm S D$ ) & $45.9 \pm 16.5$ & $42.3 \pm 13.6$ \\
\hline Female sex & 52.7 & 74.1 \\
\hline \multicolumn{3}{|l|}{ Education } \\
\hline Less than high school & 21.6 & 21.4 \\
\hline High school graduate & 19.9 & 20.4 \\
\hline Some postsecondary & 8.3 & 9.2 \\
\hline Postsecondary graduate & 50.2 & 49.1 \\
\hline \multicolumn{3}{|l|}{ Health behaviour variables } \\
\hline Cigarette consumption (current smoker) & 27.0 & 32.0 \\
\hline Alcohol dependent & 1.7 & 1.7 \\
\hline \multicolumn{3}{|l|}{ Physical activity index } \\
\hline Inactive & 56.4 & 57.4 \\
\hline Moderate & 23.5 & 23.6 \\
\hline Active & 20.1 & 19.1 \\
\hline \multicolumn{3}{|l|}{ Health care resource use } \\
\hline Family physician visits, $n$ (mean \pm SD) & $3.5 \pm 6.4$ & $5.4 \pm 6.4$ \\
\hline Specialist visits, $n$ (mean \pm SD) & $1.0 \pm 4.1$ & $1.4 \pm 2.6$ \\
\hline Visited an alternative care provider & 12.2 & 18.8 \\
\hline Hospitalized during previous year & 8.5 & 12.4 \\
\hline \multicolumn{3}{|l|}{ Chronic conditions } \\
\hline Migraine & 9.7 & 100 \\
\hline Depression & 7.5 & 17.5 \\
\hline Musculoskeletal pain & 31.2 & 48.1 \\
\hline Cardiovascular condition & 17.5 & 18.1 \\
\hline Allergic condition & 29.0 & 45.1 \\
\hline
\end{tabular}

Data presented as \% unless otherwise indicated. Note: Observations weighted by relative weights, sums equal sample size $(n=98,530)$. *Sample with all complete observations; ${ }^{\dagger}$ Characteristics of migraine sample within target sample $(n=9.7 \% \times 98,530)$.

Of the health care utilization variables, physician visits were associated with a negative health change, while having visited an alternative care provider was associated with a positive health change $(\mathrm{P}<0.05)$. Of the migraine interactions, age was associated with a negative health change, while being a postsecondary graduate was associated with a positive health change $(\mathrm{P}<0.05)$.

\section{DISCUSSION}

Our objective was to determine the relative importance of MHIAs for migraineurs by measuring the association between MHIAs and changes in health status over a one-year period. We tested this by including the interactions between having migraine and all other factors in the model, while also controlling for the relationships between health status change and age, sex, education and associated comorbidities (in their full functional forms, including interactions). We found complex 


\section{TABLE 2}

\section{Independent variable coefficients*}

\begin{tabular}{lc}
\hline Variable & Coefficient \\
\hline Health behaviour variables & \\
Current smoker (ref nonsmoker) & $-0.022^{\dagger}$ \\
Alcohol dependent (ref not alcohol dependent) & 0.002 \\
Physical activity & $0.084^{\dagger}$ \\
Health care utilization & \\
Family physician visits & $-0.005^{\dagger}$ \\
Specialist physician visits & 0.003 \\
Visited an alternative health care provider (ref no visit) & $0.058^{\dagger}$ \\
Hospitalized in the previous year (ref not hospitalized) & -0.014 \\
Interactions & \\
Migraine $\times$ age & $-0.006^{\dagger}$ \\
Migraine $\times$ sex & -0.135 \\
Migraine $\times$ age $\times$ sex & 0.004 \\
Migraine $\times$ high school graduate & 0.014 \\
Migraine $\times$ some postsecondary & 0.049 \\
Migraine $\times$ postsecondary graduate & $0.083^{\dagger}$ \\
Migraine $\times$ family physician visits & -0.002 \\
Migraine $\times$ specialist physician visits & 0.002 \\
Migraine $\times$ hospitalized in the last year & -0.044 \\
Migraine $\times$ smoking & 0.001 \\
Migraine $\times$ alcohol dependent & -0.068 \\
Migraine $\times$ physical activity & 0.024 \\
Constant & $3.217^{\dagger}$
\end{tabular}

Dependent variable: Self-reported health status change over one year. $R^{2}=0.04 ; n=98,530$. ${ }^{*}$ Coefficients for chronic conditions, demographic variables and interactions between demographic variables are not shown; tIndicates $P<0.05$. Statistical significance determined by using bootstrapgenerated standard errors. ref Reference

functional forms and interactions among the control variables that offer reassurance that the statistical control was effective.

We found a small number of interactions involving migraineurs. Notably, we found that migraineurs who were older were more likely than nonmigraineurs to report a positive health change. Also, the most highly educated migraine sufferers were more likely to report a positive health change. In terms of the MHIAs, we found that smoking was associated with negative health change, while physical activity was very strongly associated with positive health change. These relationships occurred in all individuals, including those with migraine, indicating that MHIAs do not have different effects in migraineurs than in nonmigraineurs.

Thus, MHIAs are equally important for persons with or without migraine. Previous research on the topic focused on migraineurs alone. This research showed that while intense exercise can be a trigger for migraine $(12,13,20,30)$, there is evidence suggesting that regular, moderate aerobic exercise improves cardiovascular fitness, and helps to reduce migraine frequency, severity and duration (12,13), Smoking is also a well-known risk factor for migraine $(14,18)$. Our results are new and important, because they compare migraineurs with the general population in terms of their abilities to use the resources at their disposal to 'produce' health. This is so despite the fact that the variation in health status is greater for migraineurs, as shown in Table 2 .

Furthermore, interpretation of our results provides relevant insights for migraine when viewed in the light of both noncontrollable and controllable health behavioural factors. For instance, consider a migraineur with the following characteristics: male, 46 years of age, high school graduate, not alcohol dependent, visited a family physician once, visited a specialist physician once, did not visit an alternative care provider, was not hospitalized and does not have any identified comorbidities. During the year, if this individual smoked daily and was physically inactive, he would have a reported health change of 3.1 (no change). However, if, instead, the individual did not smoke and was physically active, his reported health change would be 3.4 . Thus, by modifying controllable health behaviours, the reported health status of migraineurs can improve. However, statistically significant findings are not necessarily clinically important (31). A change in health status from 3.1 to 3.4 suggests that, if three migraineurs would stop smoking and became physically active, this would result in a one-unit improvement in health status in total. This can be achieved by a one-unit improvement in one of every three migraineurs.

A major strength of our analysis is that it is based on a national population health survey. Accordingly, our results can be taken as being representative of the entire adult migraine population. In addition, population health surveys contain information on the use of personal health resources (smoking, physical activity, use of alcohol), as well as on the use of medical health care services. Our results are therefore based on the selfreported health status of the adult migraine population and their reported behaviours under actual (nonexperimental) everyday conditions. For policy-making purposes, it is important to know the health behaviour and outcomes of persons with migraine under everyday conditions. Furthermore, while many of the variables included in our model are known to be associated with migraine independently, to our knowledge, there has been no research that has combined these variables from a perspective that explicitly views health status as a function of MHIAs.

There are, however, limitations to our approach. First, we acknowledge that the CCHS 1.1 was a cross-sectional survey and therefore precludes any causal inferences. Nonetheless, while we cannot conclude that MHIAs caused the changes in health status, an association between MHIAs and health status does exist and our findings are consistent with relevant research $(12-14,18)$. In addition, the dependent variable change in health status over the year is affected by the subjectivity of self-reported data $(32,33)$ and is a five-category outcome measure that we have treated as a continuous variable. However, relevant research on the topic has indicated that using parametric analysis on ordinal Likert data does not significantly affect Type I or Type II errors (34), or the robustness of the estimated parameter coefficients $(35,36)$. Furthermore, there is no outcome measure available on a population basis that is continuous and that measures changes in health status over time.

Second, $71.1 \%$ of our sample reported no change in health status over the year. Therefore, given that our dependent variable was change in health status over time, the degree of variance explained by our model was limited because only $29.9 \%$ experienced a change in health status. In light of this limitation however, our model fit $\left(\mathrm{R}^{2}\right)$ of $4 \%$ is comparable to other similar studies (37). Our model is also indicative of the factors that influence health change in those who experienced a change in their health status. Furthermore, although chronic conditions such as migraine last for years, there are few indicators on the health status change that are even one year in duration. 
Last, it is unknown whether migraine was diagnosed with standardized diagnostic criteria; it was identified in the CCHS 1.1 by asking respondents whether migraine had been diagnosed by a health professional. Still, our prevalence estimate of 9.7\% is similar to another Canadian population-based estimate of $8 \%$, which suggests that our definition of migraine was reliable (38).

\section{REFERENCES}

1. O'Brien B, Goeree R, Streiner D. Prevalence of migraine headache in Canada: A population-based survey. Int J Epidemiol 1994;23:1020-6.

2. Gordon KE, Dooley JM, Wood EP. Prevalence of reported migraine headaches in Canadian adolescents. Can J Neurol Sci 2004;31:324-7.

3. Clouse JC, Osterhause JT. Healthcare resource use and costs associated with migraine in managed care. Ann Pharmacother 1994;28:659-64.

4. Gilmour H, Wilkins K. Migraine. Health Rep 2001;12:23-40.

5. Cerbo R, Pesare M, Aurilia C, Rondelli V, Barbanti P. Socioeconomic costs of migraine. J Headache Pain 2001;2:S15-9.

6. Schwartz BS, Stewart WF, Simon D, Lipton RB. Epidemiology of tension-type headache. JAMA 1998;279:381-3.

7. Stewart WF, Lipton RB, Simon D. Work-related disability: Results from the American migraine study. Cephalalgia 1996;16:231-8.

8. Waldie KE, Poulton R. The burden of illness associated with headache disorders among young adults in a representative cohort study. Headache 2002;42:612-9.

9. Pryse-Phillips W, Findlay H, Tugwell P, Edmeads J, Murray TJ, Nelson RF. A Canadian population survey on the clinical, epidemiologic and societal impact of migraine and tension-type headache. Can J Neurol Sci 1992;19:333-9.

10. Lemstra M, Stewart B, Olszynski WP. Effectiveness of multidisciplinary intervention in the treatment of migraine: A randomized clinical trial. Headache 2002;42:845-54.

11. Lipton RB, Stewart WF, Celentano DD, Reed ML. Undiagnosed migraine headaches. A comparison of symptom-based and reported physician diagnosis. Arch Intern Med 1992;152:1273-8.

12. Narin SO, Pinar L, Erbas D, Oztürk V, Idiman F. The effects of exercise and exercise-related changes in blood nitric oxide level on migraine headache. Clin Rehabil 2003;17:624-30.

13. Lockett DM, Champbell JF. The effects of aerobic exercise on migraine. Headache 1992;32:50-4.

14. Chang CL, Donaghy M, Poulter N. Migraine and stroke in young women: Case-control study. The World Health Organisation Collaborative Study of Cardiovascular Disease and Steroid Hormone Contraception. BMJ 1999;318:13-8.

15. Beland Y. Canadian community health survey - methodological overview. Health Rep 2002;13:9-14.

16. Kenkel DS. Should you eat breakfast? Estimates from health production functions. Health Econ 1995;4:15-29.

17. Häkkinen U. The production of health and the demand for health care in Finland. Soc Sci Med 1991;33:225-37.

18. Sher AI, Terwindt GM, Picavet HS, Verschuren WM, Ferrari MD, Launer LJ. Cardiovascular risk factors and migraine: The GEM population-based study. Neurology 2005;64:614-20.

19. Moschiano F, D’Amico D, Schieroni F, Bussone G. Neurobiology of chronic migraine. Neurol Scis 2003;24:S94-6.

\section{CONCLUSIONS}

Our results suggest that MHIAs are as effective for persons with migraine as those without migraine; they also identify the relative importance of specific MHIAs. Smoking cessation and increased physical activity, in particular, are shown to be effective in improving health status when controlling for health service utilization and background health factors.

20. Turner-Bowker DM, Bayliss MS, Ware JE, Kosinski M. Usefulness of the SF-8 Health Survey for comparing the impact of migraine and other conditions. Qual Life Res 2003;12:1003-12.

21. Marcus DA. Gender differences in treatment-seeking chronic headache sufferers. Headache 2001;41:698-703.

22. Dahlof CG, Solomon GD. The burden of migraine to the individual sufferer: A review. Eur J Neurol 1998;5:525-33.

23. Low NC, Merikangas KR. The comorbidity of migraine. CNS Spectr 2003;8:433-44.

24. Bigal ME, Lipton RB, Krymchantowski AV. The medical management of migraine. Am J Ther 2004;11:130-40.

25. Silberstein S, Lipton R, Breslau N. Migraine: Association with personality characteristics and psychopathology. Cephalalgia 1995; 15:358-69.

26. Lipton RB, Hamelsky SW, Kolodner KB, Steiner TJ, Stewart WF. Migraine, quality of life, and depression: A population-based casecontrol study. Neurology 2000;55:629-35.

27. Terwindt GM, Ferrari MD, Tijhuis M, Groenen SM, Picavet HS, Launer LJ. The impact of migraine on quality of life in the general population: The GEM study. Neurology 2000;55:624-9.

28. Patten SB, Brandon-Christie J, Devji J, Sedmak B. Performance of the composite international diagnostic interview short form for major depression in a community sample. Chronic Dis Can 2000;21:68-72.

29. Sul Lee E, Forthofer RN, Lorimer RJ. Analyzing Complex Survey Data. London: Sage University Press, 1989.

30. Indo T, Takahashi A. Swimmer's migraine. Headache 1990;30:485-7.

31. Todd KH. Clinical versus statistical significance in the assessment of pain relief. Ann Emerg Med 1996;27:485-9.

32. Streiner DL, Norman GR. Health Measurement Scales: A Practical Guide to Their Development and Use. New York: Oxford University Press, 1995.

33. Fischer D, Stewart AL, Bloch DA, et al. Capturing the patient's view of change as a clinical outcome measure. JAMA 1999;282:1157-62.

34. Jaccard J, Wan CK. LISREL Approaches to Interaction Effects in Multiple Regression. Thousand Oaks, California: Sage Publications, 1996.

35. Binder A. Restrictions on statistics imposed by method of measurement: Some reality, some myth. J Crim Justice 1984;12:467-81.

36. Zumbo BD, Zimmerman DW. Is the selection of statistical methods governed by level of measurement? Can Psychol 1993;34:390-9.

37. Jacobs P, Schopflocher D, Klarenbach S, Golmohammadi K, Ohinmaa A. A health production function for persons with back problems: Results from the Canadian Community Health Survey of 2000. Spine 2004;29:2304-8.

38. Martin S. Prevalence of migraine in Canada. CMAJ 2001; $164: 1481$. 


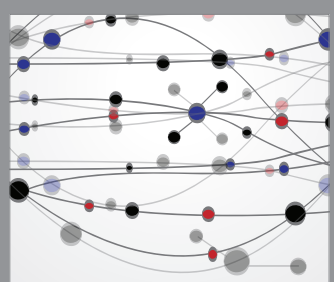

The Scientific World Journal
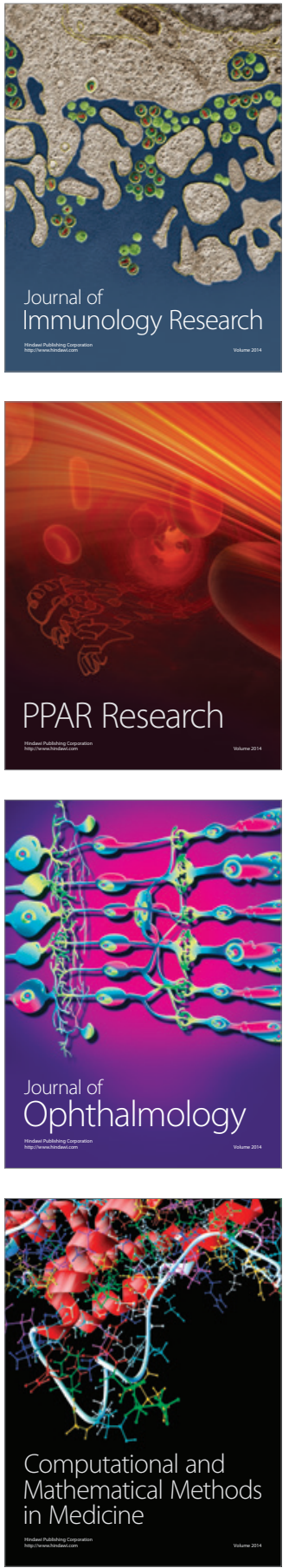

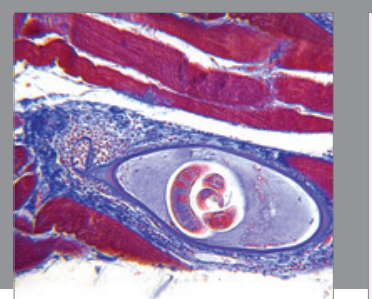

Gastroenterology Research and Practice

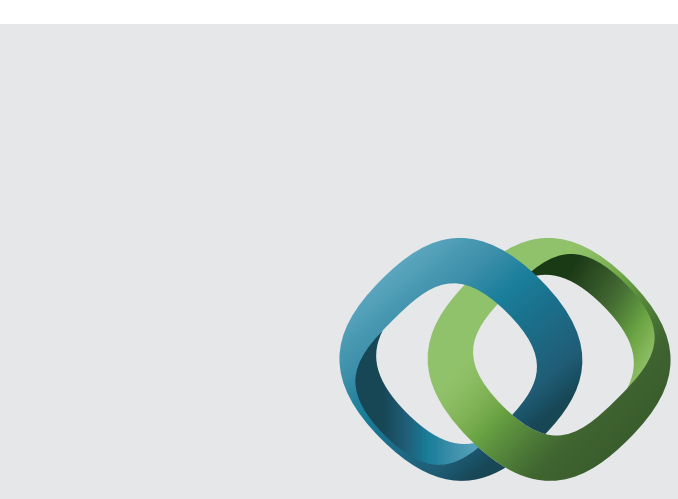

\section{Hindawi}

Submit your manuscripts at

http://www.hindawi.com
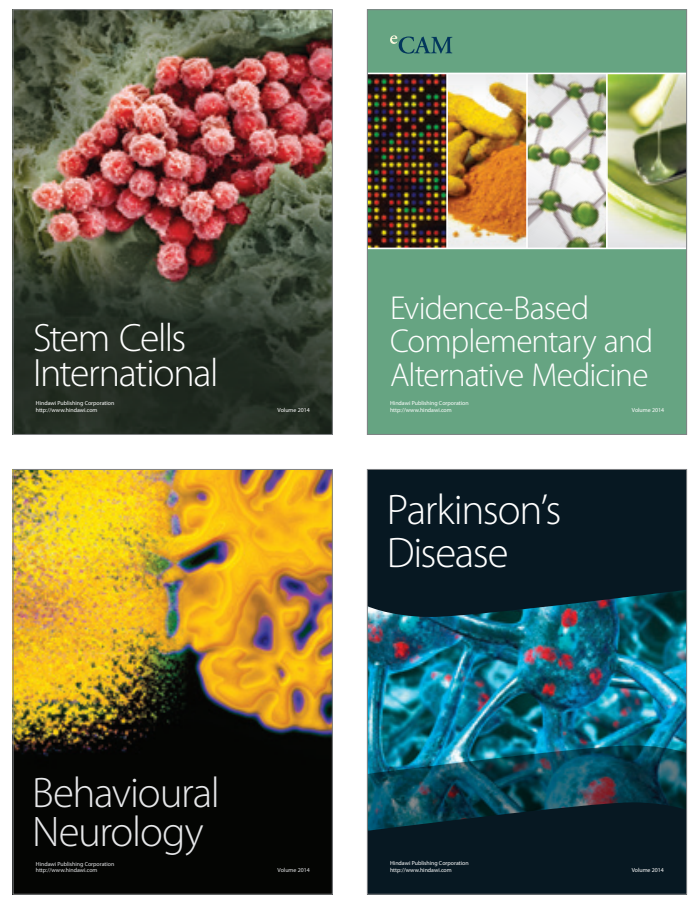
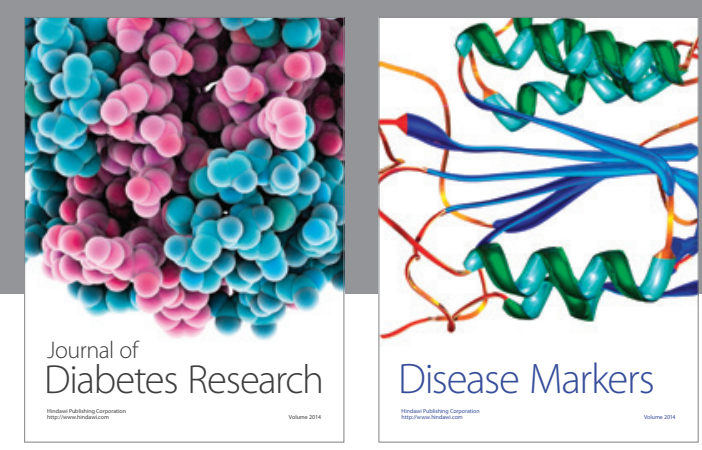

Disease Markers
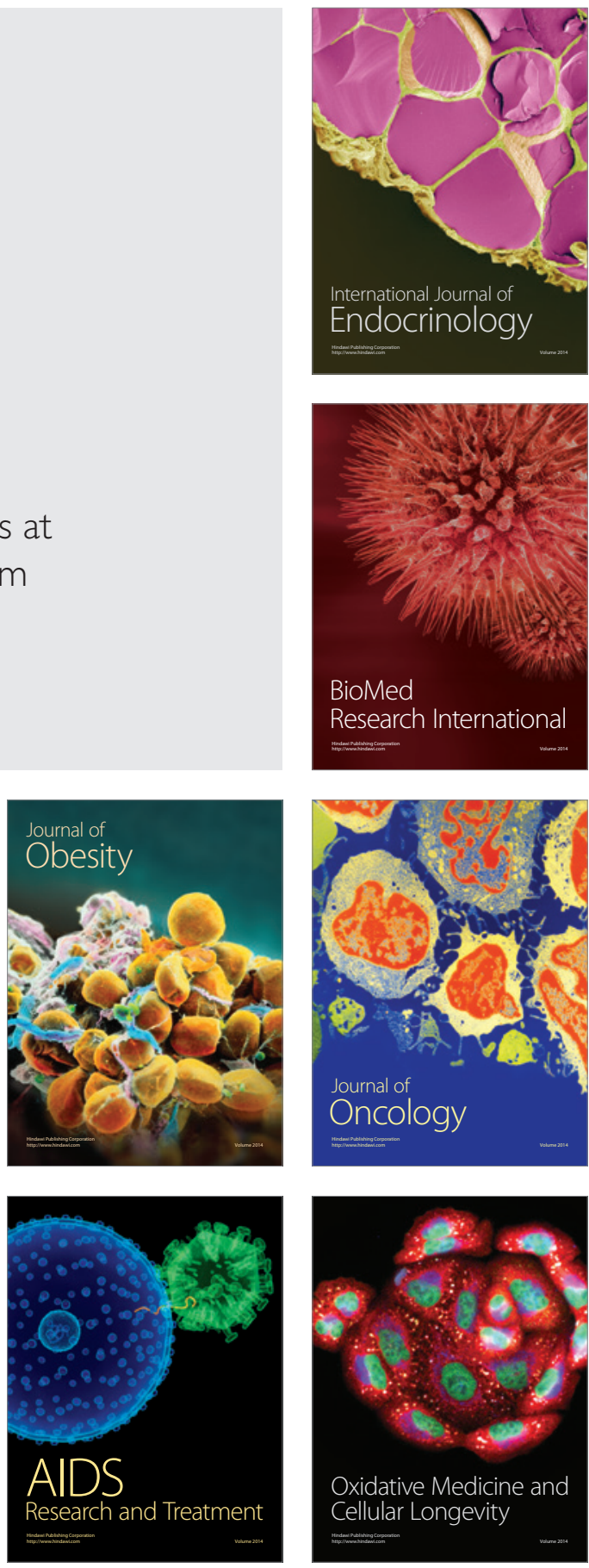